\title{
Collaborative governance platform for social innovation in Brussels
}

\author{
Laura Temmerman, Carina Veeckman and Pieter Ballon \\ IMEC-SMIT, Vrije Universiteit Brussel, Brussels, Belgium
}

\begin{abstract}
Purpose - This paper aims to share the experience of a collaborative platform for social innovation (SI) in urban governance in Brussels (Belgium) and to formulate recommendations for future initiatives.

Design/methodology/approach - The publicly funded collaborative platform "Brussels by us", which aimed to improve the quality of life in specific neighbourhoods in Brussels (Belgium), is presented as a case study for SI in urban governance. The case study is detailed according to four dimensions based on the SI and living lab literature.

Findings - While the initiative appeared to be a successful exploration platform for collaborative urban governance, it did not evolve into concrete experimentation nor implementation of the solutions. Possible explanations and recommendations are formulated.

Research limitations/implications - The findings of this paper are based on the experience of a oneyear initiative. The results should be completed by similar case studies of longitudinal initiatives, and with other levels of implementation such as experimentation and concrete implementation of solutions.

Originality/value - This paper presents a concrete case study of a collaborative platform implemented in a specific neighbourhood in Brussels (Belgium). Its digital and offline approach can help other practitioners, scholars and public institutions to experiment with the living lab methodology for the co-ideation of solution in urban governance. The four-dimensional framework presented in the study can provide future initiatives with a structured reporting and analysis framework, unifying and strengthening know-how in the domain of SI.
\end{abstract}

Keywords Brussels, Social innovation, Collaborative governance, Collaborative platform, Community participation, Living lab, Urban governance, ICT

Paper type Case study

\section{Introduction}

The rise of the recent economic, environmental and social crisis together with the increase of urbanisation is leading cities to face complex and interrelated societal issues (Baccarne et al., 2016; Govigli et al., 2020). Such “wicked problems" (Head and Alford, 2008) make it increasingly

(C) Laura Temmerman, Carina Veeckman and Pieter Ballon. Published by Emerald Publishing Limited. This article is published under the Creative Commons Attribution (CC BY 4.0) licence. Anyone may reproduce, distribute, translate and create derivative works of this article (for both commercial and noncommercial purposes), subject to full attribution to the original publication and authors. The full terms of this licence may be seen at http://creativecommons.org/licences/by/4.0/legalcode

The case study presented in this paper was funded by the State Secretary of Digital Transition of the Brussels-Capital Region (Belgium) within its Smart City framework. The authors are grateful for the participation of the citizens as well as the collaboration of the involved stakeholders of the 'Brussels by us ' project, namely: SNCB/NMBS, Befimmo, Perspective.brussels, the commune of SintJoost-ten-Noode, Beface, Brass'Art Digitaal, Creative District, Belfius, LabNorth, de Harmonie, Klavertje Vier, Bravvo, Renovas, AG Real Estate, Korei, Samenlevingsopbouw and Bouwmeester.
Collaborative governance platform 
SEJ

17,2

difficult for a single societal actor to come up with the adequate solutions (Baccarne et al., 2016) as solving them often implies negotiations between different actors (Mulgan et al., 2007). While the traditional representative democratic system has originally based its decision-making process on public institutions, experts and representatives of people's socio-economic interests (Cossetta and Palumbo, 2014), the rise of these societal issues has emphasised the need for innovative solutions in the governance domain (Chen, 2017; Wagner and Wilhelmer, 2017). Adequately addressing these challenges requires new governance models and tools that recognise and include external sources of knowledge (Baccarne et al., 2016), calling for a shift from the current top-down paradigm - where professionals and experts are seen as superiors in taking the decision regarding public policy - to a more decentralised model where citizens are engaged in the decisions that directly affect their everyday life (Anttiroiko, 2016).

Urban governance is no exception and the nature of its domain of application might even encourage this shift, as the spaces of the city are considered to be constructed through the interaction of diverse actors (Blokland, 2017). In this perspective, the urban performances of a city does not solely rely on its physical infrastructure but also on the communication of knowledge and social infrastructure (Caragliu et al., 2011). Involving citizens in the management, creation and utilisation of the urban environment is therefore believed to improve its overall performance (Nasser et al., 2019). From this perspective, participatory governance is portrayed as a way to reach democratic values such as effectiveness, legitimacy and social justice (Fung, 2015). By doing so, community collaboration would lead to social innovations (SIs) as solutions - either products, services or new models - which are able to create social value that goes beyond the capabilities of the current systems in place (Adams and Hess, 2010).

Although SI has been portrayed as a holy grail to societal problems (Adams and Hess, 2010; Ayob et al., 2016; Montgomery, 2016), it has historically received less attention than other forms of innovation such as commercial or technological innovation (Mulgan, 2006). Moreover, there is currently a lack of knowledge regarding the tools that can be designed and the processes that can be implemented to foster SI (Govigli et al., 2020). Therefore, this paper presents a case study of the collaborative platform "Brussels by us", a one-year initiative publicly funded within the smart city strategy of the Brussels-Capital Region (Belgium), and by doing so, aims to address the following two questions:

(1) To what extent was the "Brussels by us" platform an effective tool in reaching SI outcomes? To what extent can such platform foster transformative and sustainable changes?

(2) To what extent was the "Brussels by us" platform effective in fostering collaborative governance? To what extent can the usage of information and communications technology (ICT) facilitate the involvement of citizens in the community collaboration process?

Further, we aim to align the concepts of SI and living labs in the context of urban governance by proposing a structured reporting scheme composed of four dimensions: network, approaches, activities and outcomes. By applying this framework to the "Brussels by us" collaborative platform, we aim to report its process in a structured way, therefore addressing the experience, barriers and leverages of this initiative, for future initiatives and policies to build upon. Likewise, we hope to highlight reasons for policies to support SI by investing in new forms of governance such as collaborative governance while being conscious of the associated implications and requirements.

\section{Social innovation: a two-fold concept}

While SI can take several forms, from specific ideas, rules and regulations (Nicholls et al., 2015) to concepts, strategies and tools (Dawson and Daniel, 2010), the concept is currently 
defined as an open process of collaboration between diverse stakeholders (e.g. policymakers, businesses, non-governmental organisations and citizens) that changes the relationship between them by crossing organisational borders and authority, with the main goal of fostering the creation, selection and implementation of solutions that aim to address societal needs, therefore contributing to the improvement of the quality of life more effectively and fairly than existing options (Dawson and Daniel, 2010; De Filippi et al., 2017; González and Healey, 2005; Voorberg et al., 2015; Wagner and Wilhelmer, 2017). From this definition, it can be observed that the conceptualisation of SI is twofold: first as a process and second as an outcome. These two dimensions of SI have been sustained in the literature (De Filippi et al., 2017; Moulaert et al., 2005; Moulaert and MacCallum, 2019; Neumeier, 2017) and highlight the importance and necessity of both aspects: the first dimension, the process, applies the concept of community collaboration rebalancing power disparities in society and changing the social relations by involving the local community in decision-making processes; the second dimension, the outcome, embodies the answer to the social issue, aiming towards the collective satisfaction of human needs through the creation of social value (Grimm et al., 2013; Moulaert and Mehmood, 2020; Nicholls et al., 2015). However, this process-outcome distinction does not translate a linear process which would have a rational means-end trajectory, but rather highlights the importance of the creation process on its own and not only the outcome of it (Cajaiba-Santana, 2014). Indeed, as the Bureau of European Policy Advisors (Bureau of European Policy Advisers [BEPA], 2010) indicates, SI are innovations that are social both in their ends and in their means, not only answering society's need (as an outcome) but also enhancing society's capacity to act (as a process).

Community collaboration is therefore a central component of SI (Voorberg et al., 2015), involving a community of users in different stages of the decision-making processes, from the identification of the societal problem to the design phase of the solution (Govigli et al., 2020). Within this context, a community should be understood as "a group of people with diverse characteristics who are linked by social ties, share common perspectives, and engage in joint action in geographical locations or settings" (MacQueen et al., 2001, p. 1,936), therefore encompassing lay citizens, practitioners, policymakers and service agencies (Green and Mercer, 2001). Community collaboration is viewed as a social and democratic process (Pereira et al., 2017) and is anchored in the vision that "people are competent interpreters of their own lives and competent solvers of their own problems" (Mulgan, 2006, p. 150). It encompasses the exchange, work and discussion happening between different actors from different backgrounds and disciplines coming together (Ziegler, 2017) sharing their experience, expertise and resources on a specific matter. It is in this particular meet-up between different actors that new innovative ideas are being created, breaking the myth of the "individual innovation hero" working on its own towards solutions (Sørensen and Torfing, 2013).

\subsection{Collaborative urban governance}

Community collaboration can occur in different spheres of action: social organisations and enterprises, social movements, as well as in politics and governmental entities (Mulgan et al., 2007). In the framework of this paper, we will focus on urban governance, where community collaboration is also referred to as "Collaborative", "Participatory" or "Smart" governance (Ansell and Gash, 2008; Houtzager and Lavalle, 2009; Scholl and Scholl, 2014; Sørensen et al., 2020) and is defined as "the processes and structures of public policy decision making and management that engage people constructively across the boundaries of public agencies, levels of government, and/or the public, private and civic spheres in order to carry out a public purpose that could not otherwise be accomplished" (Emerson et al., 2012, p. 2). It starts from the
Collaborative governance platform 
principle that while the public sector has the objective to create public value, it does not own its monopoly and would highly benefit from the collaboration with other actors (Millard, 2013). Hence, it implies that various stakeholders are engaged in the decision-making processes on operations, policies or actions regarding public services (Harrison et al., 2012) and shared the implied responsibilities and resources (Davies and White, 2012).

To generate public value, collaborative urban governance requires appropriate sets of practices and methods. Within the domain of SI, these sets are labelled as "platforms" leading to the term "collaborative platform" (Ansell and Gash, 2018; Millard, 2013; Nambisan, 2009), which is defined as an "open environment and ecosystem with clear frameworks, guidelines, resources and supports which invites all actors to collaborate in producing public value as well as value which directly benefits the actors themselves" (Millard, 2013, p. 79). These platforms can be divided in three categories corresponding to three phases of the problem-solving process: exploration platforms, experimentation platforms and execution platforms (Nambisan, 2009). Exploration platforms are typically used to collaboratively investigate and define the nature of the unmet social need. Experimentation platforms are used to test out and evaluate the possible solutions previously identified within the community. Finally, execution platforms are used to disseminate the most relevant and successful solutions. While these three types of platforms complement each other in reaching SI, they hold different objectives and outcomes, requiring different sets of skills and resources from the involved actors, enhancing the need to adopt a so called "network" perspective (Nambisan, 2009; Taatila et al., 2006). Indeed, network support is fundamental in reaching innovation as it acts as a "mechanism to concentrate the knowledge and skills accumulated in the whole experience history of the network members" (Taatila et al., 2006, p. 320).

With the increasing power of ICT, people have asked for a more direct participation to public decision-making (Cossetta and Palumbo, 2014). Further, ICT and technological innovations allow for the real-time involvement of citizens that can both integrate and substitute the traditional forms of democratic processes (Cossetta and Palumbo, 2014). Likewise, recent technology innovations such as social media and sensors are used and applied in innovative ways, and are able to co-create knowledge and solutions at a pace that was not conceivable before the advent of the internet (Bria et al., 2015). From this point of view, ICT is often perceived as an enabler of SI (Bureau of European Policy Advisers [BEPA], 2010; Pereira et al., 2017) and is in that context referred to as "Digital Social Innovation" (van Wijk et al., 2019), which, in the form of digital collaborative platforms, holds incredible potential for urban governance (De Filippi et al., 2017). ICT has the potential to boost participation by facilitating the access to the collaborative platform, as well as in assisting in the communication of the initiative, e.g. through social media, helping to reach out to a larger population. All in all, digital collaborative platforms can enable and increase the possibilities for community collaboration, therefore supporting decision-making based on the public's needs (Pérez-González and Díaz-Díaz, 2015).

\section{Case study: the Brussels by us collaborative platform}

In this section, we present the "Brussels by us" collaborative platform, which aims to support participatory processes in the "North District" of the Brussels-Capital Region (Belgium), an area located around the north train station of Brussels in the commune of SintJoost-ten-Node (see Figure 1). This one-year initiative, running from January to December 2019, was publicly funded by the State Secretary of Digital Transition of the BrusselsCapital Region (Belgium) within the smart city framework. 


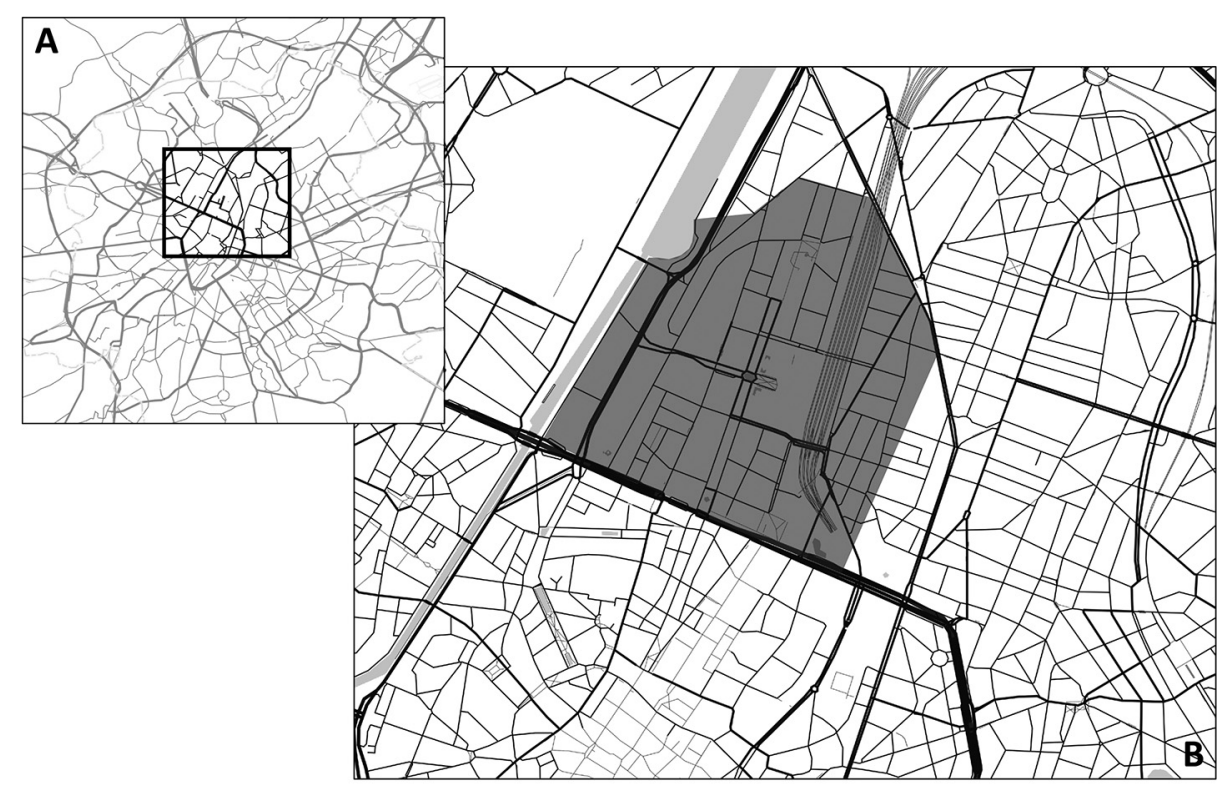

Notes: A: Location of the North District within the Brussels-Capital Region. B: In dark grey, the specific perimeter of the Living Lab zone
Collaborative governance platform

169

According to the aforementioned classification of Nambisan (2009), Brussels by us can be categorised as an "exploration platform" as its goal was to highlight concrete issues faced by citizens and to co-design, together with the local eco-system, innovative solutions that would improve citizens' quality of life. In this sense, this collaborative platform corresponds to the "design" phase of the SI co-creation framework introduced by Govigli et al. (2020). This phase corresponds to the scoping activity where implementers meet with local actors to identify the social issue and contextual factors, constituting a network of stakeholders. The network then generates a first generic idea that will be further defined in a more narrow idea and finally refined into an innovative solution. This phase usually involves a feasibility assessment which was not conducted in the scope of this initiative. The framework of Govigli et al. (2020) also includes an implementation, consolidation and evaluation phase, but these are out of the scope of this initiative.

The Brussels by us collaborative process was implemented according to a living lab methodology. The concept of collaboration, living labs and SI have long been intertwined, as living labs are defined as physical or virtual user-centric innovation environments aiming to solve societal challenges by bringing together various stakeholders for collaboration and collective ideation (Bergvall-Kåreborn et al., 2009; Hossain et al., 2019; Leminen and Westerlund, 2012). It is therefore not surprising that, within the literature, several key characteristics from living labs can be crosschecked with the SI process such as: network, approaches, activities and outcomes (Bergvall-Kåreborn et al., 2009; Cossetta and Palumbo, 2014; Govigli et al., 2020; Hossain et al., 2019; Mulgan, 2006; Neumeier, 2017). In the following section, we present these four dimensions with the aim of providing a structured reporting scheme for future SI initiatives in a living lab context, and apply it to the Brussels by us collaborative platform (see also Figure 2). 
SEJ

17,2

170

\subsection{Network}

The network represents the ecosystem of local actors, encompassing users, public authorities, companies, universities and other various institutions that bring with them their own knowledge and expertise, and will typically evolve and enlarge over time (BergvallKåreborn et al., 2009; Cossetta and Palumbo, 2014; Govigli et al., 2020; Hossain et al., 2019). Brussels by us was funded by a public authority of the Brussels-Capital Region which held the role of "promoter" of the initiative (Kronsell and Mukhtar-Landgren, 2018) by initiating the project, allocating resources and taking a municipal leadership. The collaborative platform was managed by a research centre linked to a university. The researchers therefore acted as the implementers of the project, organizing the entirety of the activities through the collaborative management of the process. Furthermore, two community managers with expertise in the North District were appointed to identify local active actors in the living lab area, and invite them to take part in the collaborative process. In total, from the 100 local entities that were contacted, 17 entities answered positively from the public sector ( 6 entities: local authorities, public services and a school), private sector (6 entities: transport, bank, real estate companies and local stores) and the associative sector (5 entities: neighbourhood associations and networking groups). The collaborative platform also enlarged its stakeholder network through its consultation and prototyping activities (see Section 3.3) and reached out to more than 370 citizens, with half of them $(\mathrm{N}=181)$ actively participating through the diverse collaborative tools (see Section 3.2). Citizens who took part in the collaborative process were mainly aged between 21 and 65 years old; $51 \%$ were male participants, $47 \%$ female participants and $2 \%$ not identifying; $43 \%$ were living in the Brussels-Capital Region, 56\% were living in Belgium but not in the Brussels-Capital Region and $1 \%$ originated from outside of Belgium. In regard to their relationship with the North District, it appeared that most of them (43\%) were either working or studying in the district, $34 \%$ were visitors of the district and $23 \%$ were living in the district.

The recruitment of the stakeholder network was done through emails and networking workshops with the public, private and associative stakeholders, while the citizens were recruited through communication via flyers, posters and press. The collaborative platform had an active website and Facebook page where information was relayed, and which allowed citizens to voice their opinions, excitement and concerns regarding the collaborative platform.

\subsection{Approaches}

The approaches are the methods, tools, (infra)structure (such as ICT) and techniques used that are fundamentally meant to involve the stakeholders in the innovation process by

Figure 2. Brussels by us collaborative platform framework

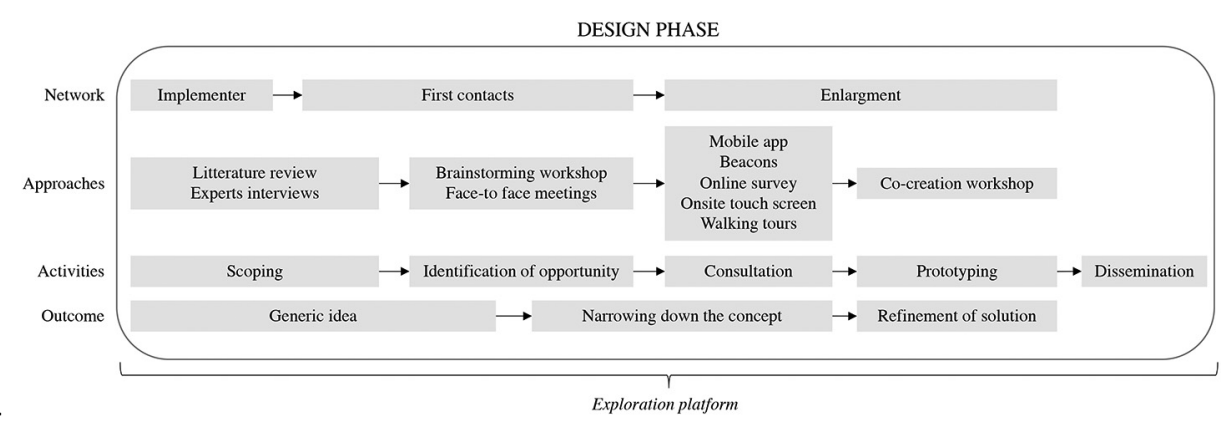


facilitating the collaboration between them (Bergvall-Kåreborn et al., 2009; Hossain et al., 2019). The collaborative platform "Brussels by us" offered two collaborative tracks complementing each other: a digital and an offline track. The offline track involved a literature review of documents and previous research reports investigating the North District, as well as face-to-face interviews with expert stakeholders and local actors, such as urban planners and civil servants. The offline track also involved brainstorming and "world café" co-creation workshops with the network of stakeholders.

The digital track consisted of a mobile application connected with beacons [1] that were installed at specific points of interest in the North District. Citizens who downloaded the app on their smartphone received location-specific questions when passing by a point of interest and could voice their opinions about ongoing and future projects while being submerged in the relevant context. This technology was reinforced with an online survey and an onsite digital touch screen, and had the purpose of enlarging the community collaboration to a wider audience. During the collection of responses, the implementers observed that the number of participants engaged via this track stayed low. To better understand the failure of this digital track in engaging citizens in the urban governance process, the implementers of the collaborative platform organised a workshop at the occasion of the PARENT project's final conference, "Building on experience: connecting people for a sustainable urban future" (5th of June 2019, Les Halles Saint-Géry, Brussels, Belgium). During this workshop, around 20 participants were asked for their feedback on the digital platform through a post-it session. Post-its and feedbacks were collected, and a thematic analysis was conducted. The session highlighted that the digital track had too many barriers: the mobile application required a registration from users, it was not sufficiently userfriendly and it required to have the Bluetooth, Global Positioning System location and mobile data features activated on the user's smartphone. Taking the collaborative process as an ongoing learning process, the implementers of the collaborative platform responded to this unforeseen aspect by organising informative walking tours where citizens could learn about the district's history as well as give their opinions through a paper survey. This element appeared to be the most successful tool in engaging citizens: most citizens participated via the paper survey (35\%), followed by the digital touch screen $(29 \%)$, the mobile application $(28 \%)$ and finally the Web survey $(8 \%)$. Participants signed a privacy statement in agreement with the General Data Protection Regulation law as well as an informed consent form prior to their participation.

\subsection{Activities}

The research activities represent the collective reflections through which SI ideas are developed and encompass collaboration activities such as the problematisation or identification of need, testing, validation, experimentation and co-creation (BergvallKåreborn et al., 2009; Govigli et al., 2020; Hossain et al., 2015; Mulgan, 2006; Neumeier, 2017). In the case of "Brussels by us", the research activities were focused on co-designing innovative ideas that would enhance citizen's quality of life in the North District. The potential innovative solutions were developed through five different phases.

Firstly, a problematisation step was carried out with the goal of defining the specific social issue of the North District according to the stakeholders' needs and demands, as well as the contextual factors. This activity was achieved through offline methods (see Section 3.2). Through this problematisation phase, it appeared that the North District was inadequately monofunctional, as it had been historically designed as a business district first and foremost. As a report from the Brussels-Capital Region describes (Doornaert et al., 2016),
Collaborative governance platform 
the North District area is mainly constituted of office buildings which accommodate for more than 40,000 employees during the day. However, the neighbourhood is also home to no less than 15,000 inhabitants, from middle class and social housing, and accommodates on average 62,000 visitors (mostly commuters), who arrive through the North Station each day. The mono-functionality together with the related lack of services and commercial offer imply that the district is busy with professionals during the day but has little activity to offer to commuters and visitors, and is deserted after office hours, leaving it as a "dead zone" not aligned with the rhythm of its residential area. Further, a thematic analysis of the brainstorming workshops organised with the network of stakeholders revealed several issues in the North District such as:

- a lack of social activities, especially in the evening;

- a lack of services and commerce;

- an area geographically "cut in half" by train tracks;

- a lack of green spaces; and

- a feeling of unsafety.

Secondly, opportunities to solve these issues were identified through face-to-face meetings with the stakeholder network, representing the first draft of generic ideas. In total, three "use cases" were identified:

- the renovation of the North train station and exploration of potential new shops, services and social activities together with the National Railway Company of Belgium (NMBS/SNCB);

- the renovation of office buildings, with an exploration of ground floors and rooftop activities together with the real estate company Befimmo; and

- the redevelopment of two railway tunnels and exploration of new urban infrastructure, services and activities together with Perspective.Brussels and the commune of Sint-Joost-ten-Node.

Based on the brainstorming workshop, several ideas answering the most prominent issues of the North District and which could be implemented in these uses cases were developed collaboratively by the network of stakeholders.

Thirdly, a large-scale consultation took place through the online participatory track. This step aimed to engage a larger number of citizens to turn the first generic ideas into narrowed down concepts. To do so, the developed ideas were presented to the citizens through the mobile application and beacon technology, as well as through the online survey, onsite digital touch screen and free informative tours in the North District for a total period of four months. The results of these surveys were analysed through a comparison of frequencies and constituted the working basis of the prototyping step.

Fourthly, the prototyping step took place through a co-creation workshop during which the solutions were further refined by the network of stakeholders. Following a "world café" fashion, participants $(n=19)$ took part in a discussion around the use cases and related results. Inputs were audio-recorded while the researchers took additional notes. A thematic analysis was conducted, and the final outcomes were embodied as visual prototypes of ideas for each use case (see Section 3.4).

Fifthly, the visual prototypes of the "Brussels by us" collaborative platform were delivered to the Brussels-Capital Region, and shared with the network of stakeholders. They were accompanied by a description of the solutions and ways to implement them. 


\subsection{Outcomes}

The innovation outcomes can either be tangible (products, prototypes, designs, etc.) or intangible (ideas, knowledge, services, etc.) (Hossain et al., 2019) and evolved from broad to narrow through collaborative activities (Govigli et al., 2020). The outcomes of the "Brussels by us" collaborative platform were formulated as generic concepts during the problematisation and identification phases, where the use cases were identified as ground for solutions. From there, the concepts were narrowed down during the brainstorming workshops and the large-scale consultation of citizens. Finally, the ideas were refined during a last co-creation workshop. The outcomes take the form of visual prototypes representing the innovative ideas co-created by the stakeholder network. The following paragraphs describe the final outcomes of the collaborative process.

Regarding the North Station case, the stakeholder network agreed that the station was overall unattractive, cold and closed on itself. Altogether, the station is currently neither benefiting the inhabitants, professionals nor the visitors. The local community emphasized the need for better and more diversified type of services, social activities and shops. An old unused space of the North Station was chosen by the community as an ideal place to make the station a livelier and more connected place. The space was conceived as an "interaction hub" which would serve a multifunction purpose while attracting different profile of citizens together, creating interaction and connection between them. In terms of services, the community determined that a public library would be ideal for the inhabitants as the district is currently missing one, and would also provide commuters with a convenient location for them to borrow books, on their way to and from work. The library could be supplemented with a waiting room, offering commuters and visitors with a cosy spot to spend time, relax and connect with other people, as stated by one participant:

[... . not every empty spaces should be commercialized, there is currently not enough waiting area in the station [ . . . ]if I want to wait in a quiet place for my train [ . . . ] where do I go?

As the professional population of the district represents a large number of citizens, it was logical to address one of their apparent needs: a co-working space. Although the North District is mainly a professional district, it appeared that a co-working space was still missing. It was envisioned to be located at the first level of the old museum, above the library. The co-working space would allow professionals of the district to work in another setting, it would provide the visitors of the zone travelling to Brussels with a comfortable space to work remotely, and to the inhabitants of the zone it would provide a quiet place to work or study: "[. . . it could bring people together, provide them with a modular space, whether for a presentation or to work quietly". This variety of profiles would allow synergies and opportunities to happen. Finally, a food market would also be present on the ground floor of the former museum, providing inhabitants, professionals and visitors with local and healthy products. The local market area would also host a kitchen spot that local associations could manage and use at their convenience for cooking together with social vulnerable groups living in the area (see Figure 3).

Regarding the second use case, the renovation of office buildings, ground floors and rooftops, the stakeholder network agreed that there was a lack of services and shops in this specific part of the district. Professionals and inhabitants currently have to travel to the centre of Brussels to have diversified lunch and drink options. Therefore, food trucks were seen as the perfect solution as it is flexible in its offer and location, meeting the needs of different groups of citizens. Furthermore, the community had the idea to occupy the currently unused ground floors of some buildings. There, a "community hub" could open, 
Figure 3.

Co-created visual regarding the "North station" use case

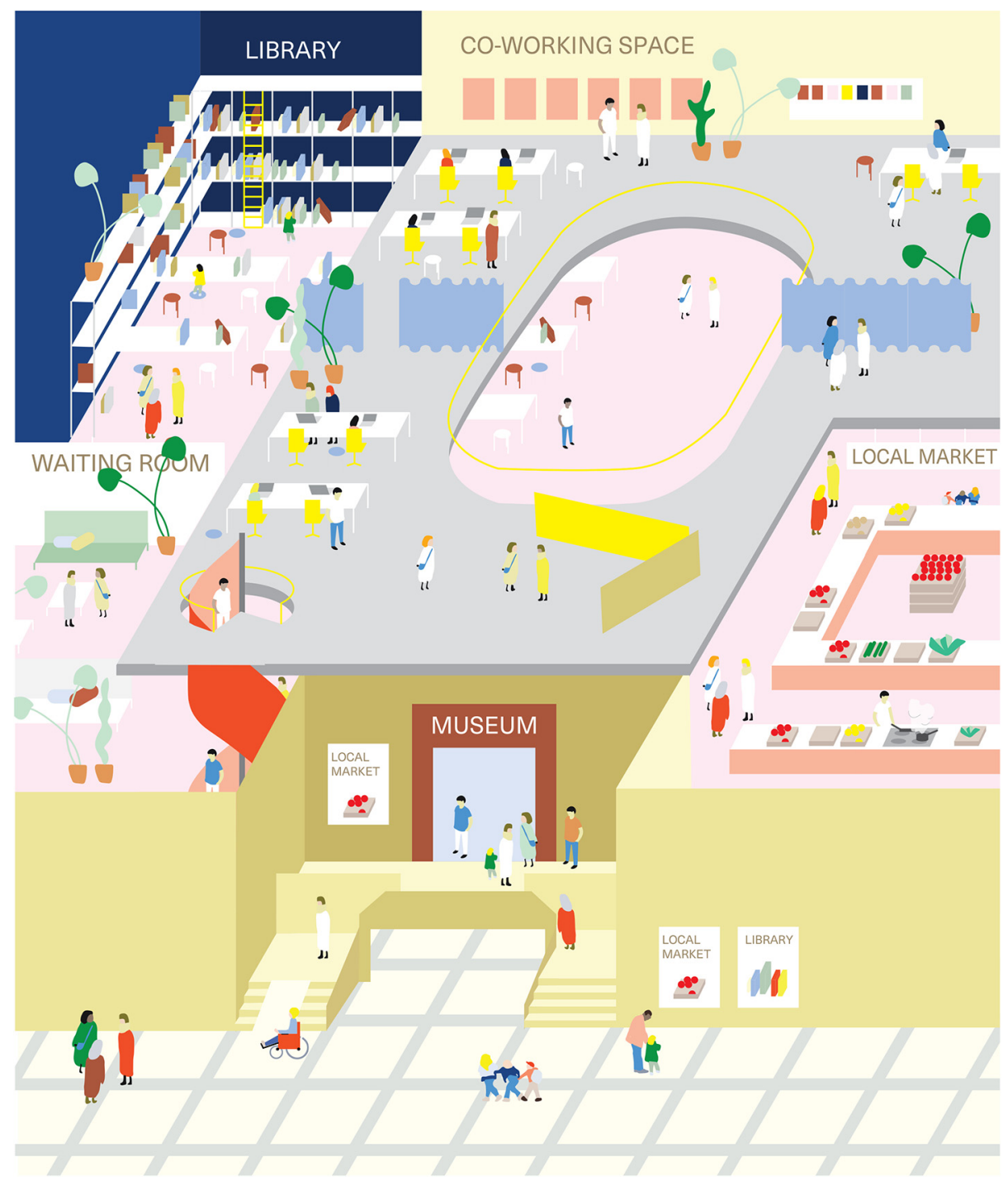

benefiting the whole community of the North District. Different types of activities could be organised, bringing people from different backgrounds together. Next to it, a cosy coffee place could open and could communicate with the community hub. A cultural centre was also seen as beneficial by the community. It could provide the local artists and students of the district with a showcase spot for their creations. Classes and workshops on various subjects could also be organised at the location. On the unused rooftops of some buildings, urban gardens could be managed by the local community and schools of the district:

$[\ldots]$ the vegetables that are grown on the rooftops could be served in the district, and the leftovers could be taken back into compost bins [. . . ] like in a circular fashion. 
Working together with the local market of the North Station, it could help feed the less privileged of the district. For example, local associations could use the harvest of the urban garden to cook for the migrants currently residing in the North Station (see Figure 4).

Finally, in regard to the use case of the tunnels, the community emphasised the need for better urban infrastructure at these locations as opposed to shops and services. Indeed, the tunnels were seen as very unpleasant, dark and smelly, and the community was overall feeling insecure when walking past it. This is a critical element as the tunnels link together different parts of the district: if the community is uncomfortable and does not use them, it can create a feeling of isolation from one side to the other. To remedy to this issue and foster a sense of comfort in the tunnels, the community saw lightning as the most important

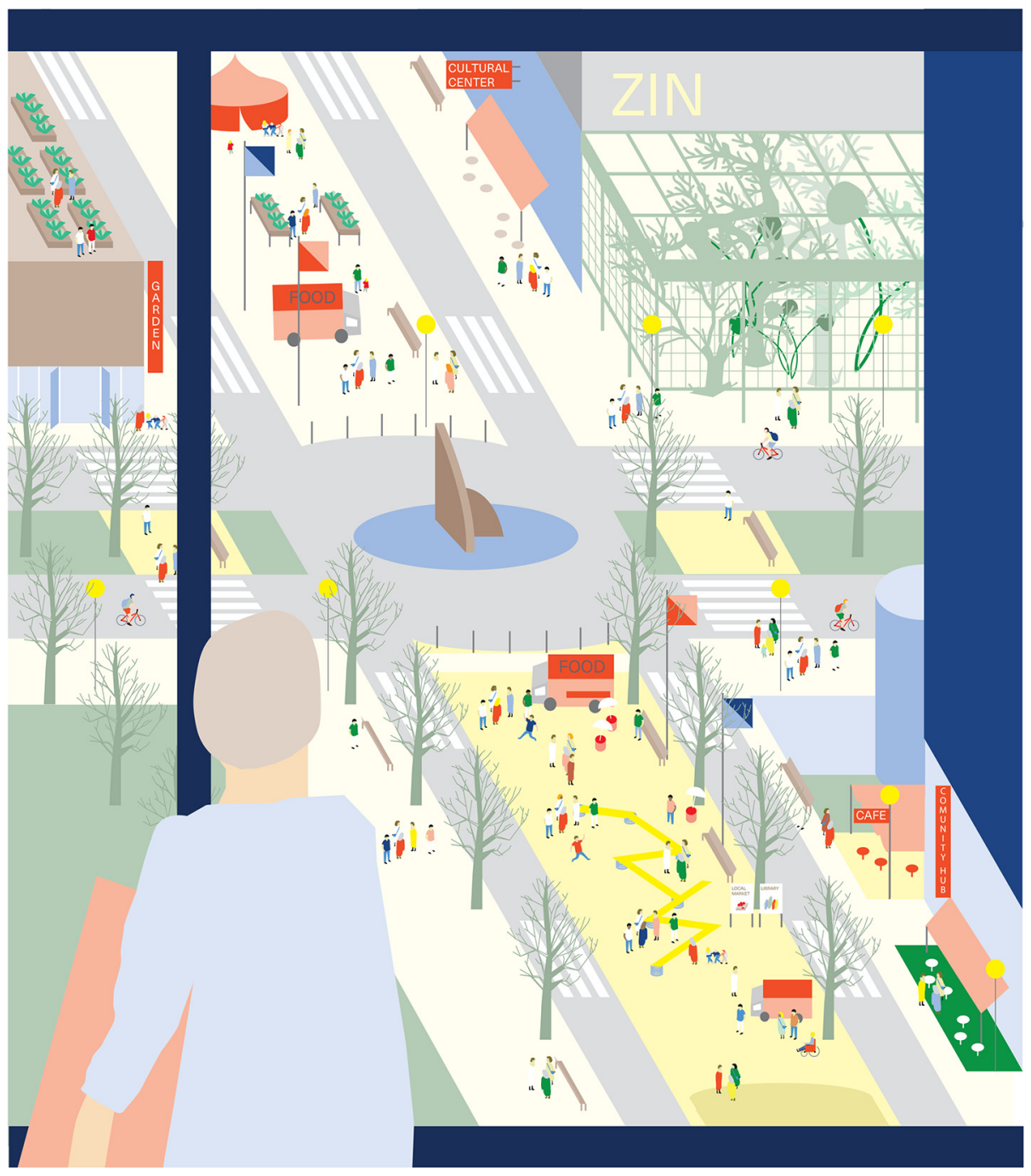

Collaborative governance platform 
adjustment to be made, as stated by this participant, and confirmed by all, "Improve the lightning - day and night! - would already make a difference". The visual appearance of the tunnels was also seen as problematic. Therefore, the community pointed out the need for elements to counteract the mineral aspect of the tunnels, such as low-light plants and art pieces exposed on the walls of the tunnels, "We could have mushrooms or moss [...] there exist a kind of paint that you use, and moss grows out of it". A water stream running down the tunnels was also seen as a solution to both water the plants and get rid of unwanted smells that could linger at these locations. Finally, food trucks and other temporal activities and services were seen as a pole of attraction that would bring together the local community of both sides of these tunnels: "A line up of food trucks could give a reason for people to go there, food is a good reason [. . . ] you're always hungry!" (see Figure 5).

\section{Discussion}

\subsection{Collaborative platform for social innovation in Brussels}

Brussels by us was an exploration platform used to collaboratively investigate and define the nature of issues in the North District, and co-design possible solutions. In this sense, the sequence of activities from the problematisation to the final prototype were successful in formulating innovative solutions (embodied as visual prototypes), answering the local needs of the community. However, the timing of the initiative had an impact on its management plan, leading the process to start from use cases and explore from there the innovative solutions that could be implemented, instead of the opposite often recommend in SI. This implies that, although the ideas co-designed in the context of the "Brussels by us" initiative are relevant for the district, they might not answer the most pressing social issues for the community. Further, the time resources restricted the possibilities for specific adjustments in the process and more in-depth understanding of the social issues of the district. Likewise, more time would have allowed for longer and more diversified communication and engagement activities, leading to an increase in the awareness regarding the initiative, and possibly larger participation. To allow for further investigation of the most pressing social needs of the community and to reach out to a larger number of citizens, practitioners should allow for a longer period of investigation.

Although the collaborative platform was successful in its design phase, the implementation, consolidation and evaluation phases described by Govigli et al. (2020) were left out of the initiative. While these phases were originally not foreseen in the proposal plan of the initiative, it was expected that the results would be implemented by the network of stakeholders. However, during the dissemination phase of the initiative, issues popped up regarding the responsibility of the stakeholder network in taking up and implementing the solutions, accentuated by the distinctive authorities of the actors in this urban context. This emphasises the importance of the role of governmental actors constituting the stakeholder network in SI initiatives: collaboration in the implementation of SI solutions is as crucial as in their co-design to create and sustain public value. This is particularly imperative when solutions fall under the jurisdiction of particular actors, as it can be the case when talking about public space (Ansell and Gash, 2008; Kronsell and Mukhtar-Landgren, 2018). It is not uncommon for social initiatives in the domain of urban governance to be faced with resistance and interagency competition as was the case for the "Brussels by us" collaborative platform. As Bartels (2017) explains, the existing power relations and institutional configuration can inhibit SI as such initiatives are, by nature, disruptive. This can lead to the so-called "Janus-face" of collaborative governance where the state 


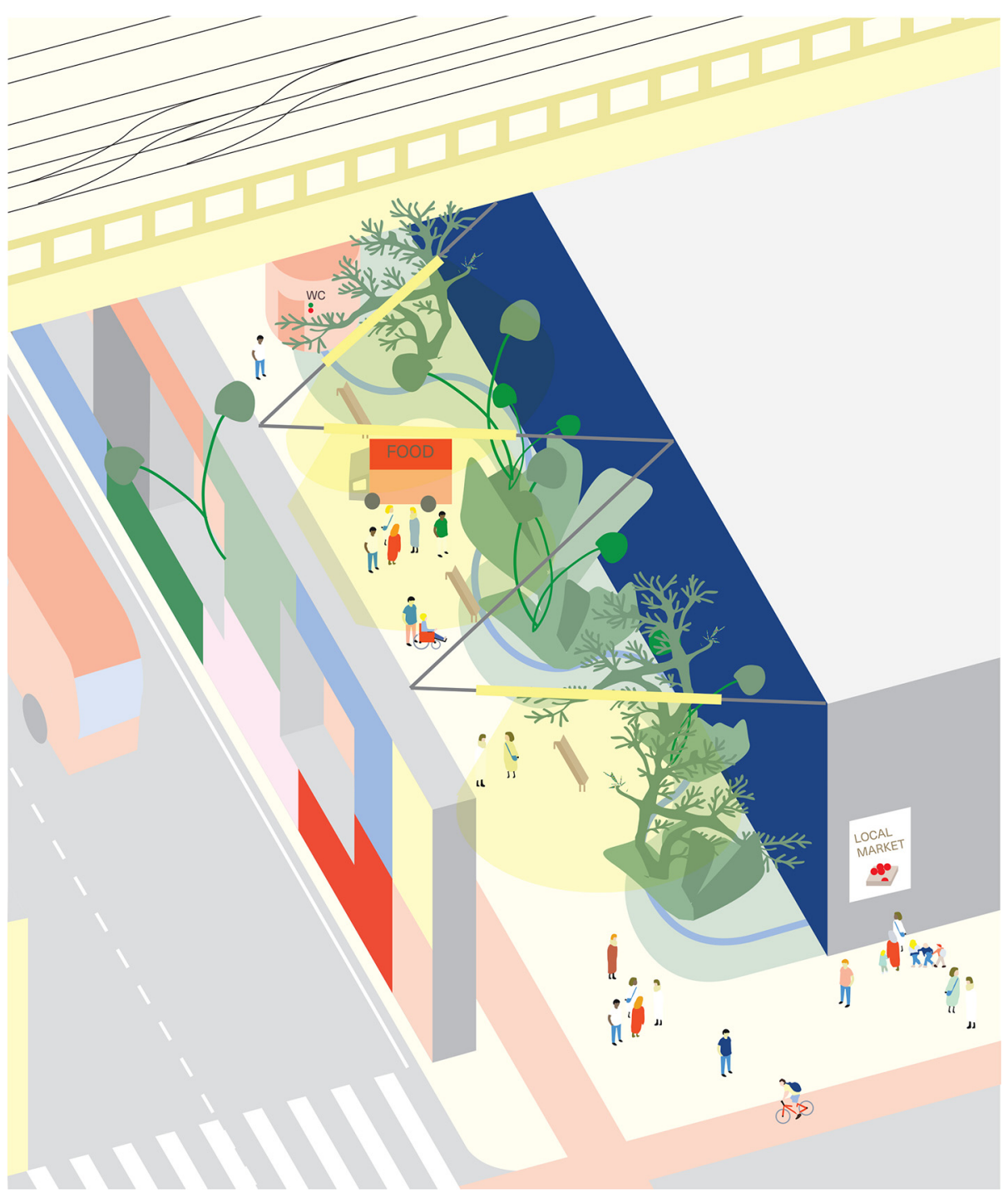

Collaborative governance platform

is setting up collaborative governance initiatives but is at the same resisting the change generated by new forms of governance (Swyngedouw, 2005). This illustrates that, on the one hand, implementers should not only focus on engaging the local community but also be ready to face possible resistance from the government. On the other hand, governmental actors should be aware that SI requires change and transformation from their current top-down structure. This could be facilitated if governmental actors moved from the role of "promoter" of initiatives to the role of "enabler" or "partner", sharing leadership and having a distinct function in the collaborative process (Kronsell and Mukhtar-Landgren, 2018). 
SEJ

17,2

\subsection{Collaborative platform for collaborative governance in Brussels}

While the first goal of the "Brussels by us" collaborative platform was to co-design innovative ideas that would enhance citizen's quality of life in the North District, the initiative had the overarching goal of investigating if the collaborative platform, and more specifically the usage of ICT in the form of sensors and a mobile application, could facilitate the involvement of citizens and foster community collaboration within the urban governance process. It was proved imperative for the collaborative process to adopt both an online and offline trajectory that complemented each other. Firstly, while it was first assumed that the online track would enlarge community participation, the mobile application and beacon technology failed at this task, and the offline track appeared to be the most appealing to citizens. Secondly, including a paper survey during the informative walking tours in the North District enabled the initiative to be more inclusive as the only use of digital tools can lead to a "digital divide", representing the fact that digital tools are not used by the entirety of the population (Effing and Groot, 2016). We observed that older participants (above 50 years old) engaged preferentially via the paper survey $(72.2 \%)$ as compared to the mobile app $(15.2 \%)$ and Web survey $(12.5 \%)$. The role of these small-scale events was crucial in engaging the community. Future initiatives should not underestimate their power and could imagine other type of activities such as the "cleaning events" reported by Bartels (2017).

Furthermore, a feeling of distrust was often relayed in the comment section of the communication led by the "Brussels by us" initiative on the dedicated Facebook page as well as in direct emails, which could explain the relative low numbers in terms of active participation. People stated not wanting to take part in such an initiative as they already knew that their opinion as citizens would not be listen to. Several communication efforts were made to turn this around, but it is to be expected that the feeling would stay unchanged until proven otherwise. Moreover, several collaborative platforms were running at the same time in Brussels, leading to a certain confusion regarding each platform's goals and process. The communications regarding the initiatives were coming from several entities, and neither unified vision nor presentation was done by an official actor. It is hypothesised that this had an influence not only on the Brussels by us initiative, but also on the other collaborative platforms. Therefore, we recommend future initiatives as well as official entities to work together towards a united discourse on participation. More specifically, future initiatives should work with relevant and well-known entities in the local community, as a lack of perceived legitimacy of the implementer of the collaborative platform - in this case, the research centre affiliated with a university - from a citizen's perspective can lead to the failure of the SI (van der Have and Rubalcaba, 2016).

\section{Conclusions}

In sum, this case study analysis demonstrates the complexity of supporting and implementing a (digital) collaborative platform. Through the presentation of a fourdimensional framework for SI in a living lab context, we aim to provide practitioners, scholars and public institutions with a structured reporting and analysis scheme that would unify and strengthen know-how in the domain of SI. Future initiatives can build upon the lessons learned of the "Brussels by us" initiative to go from an exploration to an experimentation and later on, to an execution platform leading to tangible social value.

In this paper, we argued that the fundamental process of SI is executed through community collaboration which is embodied in the context of urban governance by collaborative governance. To attain collaborative governance, ICT is often viewed as an enabler helping to reach out to a maximum of participants. However, we have highlighted 
the important role of offline trajectories: while the mobile app had the potential to, theoretically, reach a large number of citizens, they were a number of factors that limited that possibility. From our experience, relying solely on ICT in a collaborative process is not an ideal choice. Future collaborative platforms including an ICT tool should lower any barriers to its usage, and if possible, run a trial period before the project's beginning. Moreover, future initiatives should adapt their tools and methods to the local context and should not underestimate the engagement power of small-scale events. As such, the timeframe of the initiative has to be assessed in consideration of the goals of the initiative (whether it be an exploration, experimentation or execution platform), as well as to allow for potential readjustments of the methods and techniques used in the collaborative process. Likewise, practitioners should be aware of the time and efforts that constituting a network requires. More specifically, extensive communication efforts have to be made to accurately describe the collaborative platform and its goal to the community, and engage them in the collaborative process, requiring an extensive amount of time, money and expertise. Finally, practitioners should not underestimate the efforts required to involve the relevant actors in the project while constituting their network both from the local community and from the governmental side. Future initiatives should strive to involve governmental entities as partner in their own rights rather than as mere promoter by making sure they hold a distinct function and share an active leadership in the collaborative process.

To conclude, while it is in the interest of governmental actors to fund SI initiatives and collaborative governance projects to build a more open and democratic society, they should be aware that such initiatives requires efforts to be turned into effective social value. Actions have to be taken up on each level, including the governmental level, to activate their outcomes into transformative and sustainable societal impact.

\section{Note}

1. Beacons are small Bluetooth transmitters that send out a Bluetooth signal. This signal is read by Bluetooth-equipped device such as smartphones. For the smartphone to read the signal, a related mobile application must be downloaded. When entering the range of a beacon (approximately 100-m range), the app is then triggered by the signal of the beacon and sends out a notification to the smartphone.

\section{References}

Ansell, C. and Gash, A. (2008), "Collaborative governance in theory and practice", Journal of Public Administration Research and Theory, Vol. 18 No. 4, pp. 543-571, available at: https://doi.org/ 10.1093/jopart/mum032

Adams, D. and Hess, M. (2010), "Social innovation and why it has policy significance", The Economic and Labour Relations Review, Vol. 21 No. 2, pp. 139-155, available at: https://doi.org/10.1177/ 103530461002100209

Ansell, C. and Gash, A. (2018), "Collaborative platforms as a governance strategy", Journal of Public Administration Research and Theory, Vol. 28 No. 1, pp. 16-32, available at: https://doi.org/ 10.1093/jopart/mux030

Anttiroiko, A.-V. (2016), "City-as-a-Platform: the rise of participatory innovation platforms in Finnish cities”, Sustainability, Vol. 8 No. 9, p. 922, available at: https://doi.org/10.3390/su8090922

Ayob, N., Teasdale, S. and Fagan, K. (2016), "How social innovation 'came to be': tracing the evolution of a contested concept”, Journal of Social Policy, Vol. 45 No. 4, pp. 635-653, available at: https:// doi.org/10.1017/S004727941600009X 
Baccarne, B., Logghe, S., Schuurman, D. and De Marez, L. (2016), "Governing quintuple helix innovation: urban living labs and socio-ecological entrepreneurship", Technology Innovation Management Review, Vol. 6 No. 3, pp. 22-30, available at: http://dx.doi.org/10.22215/timreview/972

Bartels, K. (2017), "The double bind of social innovation: relational dynamics of change and resistance in neighbourhood governance", Urban Studies, Vol. 54 No. 16, pp. 3789-3805, available at: https://doi.org/10.1177/0042098016682935

Bureau of European Policy Advisers (BEPA) (2010), "Empowering people, driving change: social innovation in the European Union".

Bergvall-Kåreborn, B., Eriksson, C.I., Ståhlbröst, A., and Svensson, J. (2009), "A milieu for innovation: defining living labs", Presented at the ISPIM Innovation Symposium, 06/12/2009-09/12/2009.

Blokland, T. (2017), Community as Urban Practice, John Wiley and Sons.

Bria, F., Sestini, F., Gasco, M., Baeck, P., Halpin, H., Almirall, E. and Kresin, F. (2015), "Growing a digital social innovation ecosystem for Europe: DSI final report”, Bruss. Eur. Comm.

Cajaiba-Santana, G. (2014), "Social innovation: Moving the field forward. A conceptual framework", Technological Forecasting and Social Change, Vol. 82, pp. 42-51, available at: https://doi.org/ 10.1016/j.techfore.2013.05.008

Caragliu, A., Bo, C.D. and Nijkamp, P. (2011), "Smart cities in”, Journal of Urban Technology, Vol. 18 No. 2, pp. 65-82, available at: https://doi.org/10.1080/10630732.2011.601117

Chen, M.-X. (2017), "Research on social governance innovation during social transformation period", DEStech Transactions on Social Science, Education and Human Science, No. icssd, available at: https://doi.org/10.12783/dtssehs/icssd2017/19217

Cossetta, A. and Palumbo, M. (2014), "The co-production of social innovation: the case of living lab", in Dameri, R.P. and Rosenthal-Sabroux, C. (Eds), Smart City: How to Create Public and Economic Value with High Technology in Urban Space, Progress in IS, Springer International Publishing, Cham, pp. 221-235, available at: https://doi.org/10.1007/978-3-319-06160-3_11

Davies, A.L. and White, R.M. (2012), "Collaboration in natural resource governance: reconciling stakeholder expectations in deer management in Scotland", Journal of Environmental Management, Vol. 112, pp. 160-169, available at: https://doi.org/10.1016/j.jenvman.2012.07.032

Dawson, P. and Daniel, L. (2010), "Understanding social innovation: a provisional framework", International Journal of Technology Management, Vol. 51 No. 1, p. 9, available at: https://doi.org/ 10.1504/IJTM.2010.033125

De Filippi, F., Coscia, C. and Cocina, G.G. (2017), "Collaborative platforms for social innovation projects. The Miramap case in Turin”, Techne-J. Technol. Archit. Environ, Vol. 14, pp. 219-226.

Doornaert, A., Demeuter, P. and Hanssens, B. (2016), "Office property observatory: 2015 vacancy in Brussels and focus on the North District".

Effing, R. and Groot, B.P. (2016), "Social smart city: introducing digital and social strategies for participatory governance in smart cities", in International Conference on Electronic Government, Springer, Cham, pp. 241-252.

Emerson, K., Nabatchi, T. and Balogh, S. (2012), "An integrative framework for collaborative governance", Journal of Public Administration Research and Theory, Vol. 22 No. 1, pp. 1-29, available at: https://doi.org/10.1093/jopart/mur011

Fung, A. (2015), "Putting the public back into governance: the challenges of citizen participation and its future", Public Administration Review, Vol. 75 No. 4, pp. 513-522, available at: https://doi.org/ 10.1111/puar.12361

González, S. and Healey, P. (2005), "A sociological institutionalist approach to the study of innovation in governance capacity”, Urban Studies, Vol. 42 No. 11, pp. 2055-2069, available at: https://doi.org/ 10.1080/00420980500279778

Govigli, V.M., Alkhaled, S., Arnesen, T., Barlagne, C., Bjerck, M., Burlando, C., Melnykovych, M., Rodríguez Fernandez-Blanco, C., Sfeir, P. and Górriz-Mifsud, E. (2020), "Testing a framework to co-construct social innovation actions: insights from seven marginalized rural areas", Sustainability, Vol. 12 No. 4, p. 1441, available at: https://doi.org/10.3390/su12041441 
Green, L.W. and Mercer, S.L. (2001), "Can public health researchers and agencies reconcile the push from funding bodies and the pull from communities?", American Journal of Public Health, Vol. 91 No. 12, pp. 1926-1929, available at: https://doi.org/10.2105/AJPH.91.12.1926

Grimm, R., Fox, C., Baines, S. and Albertson, K. (2013), "Social innovation, an answer to contemporary societal challenges? Locating the concept in theory and practice", Innovation: The European Journal of Social Science Research, Vol. 26 No. 4, pp. 436-455, available at: https://doi.org/10.1080/ 13511610.2013.848163

Harrison, T.M., Guerrero, S., Burke, G.B., Cook, M., Cresswell, A., Helbig, N., Hrdinova, J. and Pardo, T. (2012), "Open government and e-government: democratic challenges from a public value perspective", Information Polity, Vol. 17 No. 2, pp. 83-97, available at: https://doi.org/10.3233/IP-2012-0269

Head, B. and Alford, J. (2008), "Wicked problems: implications for policy and management", Presentation Delivered to the Australasian Political Studies Association Conference, pp. 6-9.

Hossain, M., Leminen, S. and Westerlund, M. (2019), "A systematic review of living lab literature", Journal of Cleaner Production, Vol. 213, pp. 976-988, available at: https://doi.org/10.1016/j. jclepro.2018.12.257

Hossain, M.M., Scott, I.M., McGarvey, B.D., Conn, K., Ferrante, L., Berruti, F. and Briens, C. (2015), "Insecticidal and anti-microbial activity of bio-oil derived from fast pyrolysis of lignin, cellulose, and hemicellulose", Journal of Pest Science, Vol. 88 No. 1, pp. 171-179, available at: https://doi. org/10.1007/s10340-014-0568-4

Houtzager, P.P. and Lavalle, A.G. (2009), "Participatory governance and the challenge of assumed representation in Brazil", IDS Working Papers, Vol. 2009 No. 321, pp. 01-32, available at: https:// doi.org/10.1111/j.2040-0209.2009.00321_2.x

Kronsell, A. and Mukhtar-Landgren, D. (2018), "Experimental governance: the role of municipalities in urban living labs", European Planning Studies, Vol. 26 No. 5, pp. 988-1007, available at: https:// doi.org/10.1080/09654313.2018.1435631

Leminen, S. and Westerlund, M. (2012), "Towards innovation in living labs networks", International Journal of Product Development, Vol. 17 Nos 1/2, pp. 43-59, available at: https://doi.org/10.1504/ IJPD.2012.051161

MacQueen, K.M., McLellan, E., Metzger, D.S., Kegeles, S., Strauss, R.P., Scotti, R., Blanchard, L. and Trotter, R.T. (2001), "What is community? An evidence-based definition for participatory public health”, American Journal of Public Health, Vol. 91 No. 12, pp. 1929-1938, available at: https://doi. org/10.2105/AJPH.91.12.1929

Millard, J. (2013), "ICT-enabled public sector innovation: trends and prospects", in Proceedings of the 7th International Conference on Theory and Practice of Electronic Governance, ICEGOV '13, ACM, New York, NY, pp. 77-86, available at: https://doi.org/10.1145/2591888.2591901

Montgomery, T. (2016), “Are social innovation paradigms incommensurable? Volunt”, Voluntas: International Journal of Voluntary and Nonprofit Organizations, Vol. 27 No. 4, pp. 1979-2000, available at: https://doi.org/10.1007/s11266-016-9688-1

Moulaert, F. and MacCallum, D. (2019), Advanced Introduction to Social Innovation, Edward Elgar Publishing.

Moulaert, F. and Mehmood, A. (2020), "Towards a social innovation (SI) based epistemology in local development analysis: lessons from twenty years of EU research", European Planning Studies, Vol. 28 No. 3, pp. 434-453, available at: https://doi.org/10.1080/09654313.2019.1639401

Moulaert, F., Martinelli, F., Swyngedouw, E. and Gonzalez, S. (2005), "Towards alternative model(s) of local innovation”, Urban Studies, Vol. 42 No. 11, pp. 1969-1990, available at: https://doi.org/ $10.1080 / 00420980500279893$

Mulgan, G. (2006), "The process of social innovation”, Innov. Technol. Gov. Glob, Vol. 1 No. 2, pp. 145-162, available at: https://doi.org/10.1162/itgg.2006.1.2.145

Mulgan, G., Tucker, S., Ali, R. and Sanders, B. (2007), "Social innovation: what it is, why it matters and how it can be accelerated [WWW document]", available at: http://eureka.sbs.ox.ac.uk/761/ (accessed 12.10.19). 
Nambisan, S. (2009), "Platforms for collaboration”, Stanf. Soc. Innov. Rev, Vol. 7, pp. 44-49.

Nasser, B., Fardin, H. and Mani, S.F. (2019), "Towards a democratic process in urban planning and design”, Assessing the Status of Citizens' Involvement in Urban Plans and Projects in Iran, Vol. 16, pp. 5-20.

Neumeier, S. (2017), "Social innovation in rural development: identifying the key factors of success", The Geographical Journal, Vol. 183 No. 1, pp. 34-46, available at: https://doi.org/10.1111/geoj.12180

Nicholls, A., Simon, J., Gabriel, M. and Whelan, C. (2015), New Frontiers in Social Innovation Research, Springer.

Pereira, G.V., Cunha, M.A., Lampoltshammer, T.J., Parycek, P. and Testa, M.G. (2017), "Increasing collaboration and participation in smart city governance: a cross-case analysis of smart city initiatives", Information Technology for Development, Vol. 23 No. 3, pp. 526-553, available at: https://doi.org/10.1080/02681102.2017.1353946

Pérez-González, D. and Díaz-Díaz, R. (2015), "Public services provided with ICT in the smart city environment: the case of Spanish cities".

Scholl, H.J. and Scholl, M.C. (2014), "Smart governance: a roadmap for research and practice", available at: https://doi.org/10.9776/14060

Sørensen, E. and Torfing, J. (2013), "Enhancing social innovation by rethinking collaboration, leadership and public governance", NESTA Soc. Front.

Sørensen, E., Hendriks, C.M., Hertting, N. and Edelenbos, J. (2020), "Political boundary spanning: politicians at the interface between collaborative governance and representative democracy", Policy Soc, pp. 1-40, available at: https://doi.org/10.1080/14494035.2020.1743526

Swyngedouw, E. (2005), "Governance innovation and the citizen: the Janus face of governance-beyondthe-state", Urban Studies, Vol. 42 No. 11, pp. 1991-2006, available at: https://doi.org/10.1080/ 00420980500279869

Taatila, V.P., Suomala, J., Siltala, R. and Keskinen, S. (2006), "Framework to study the social innovation networks”, European Journal of Innovation Management, Vol. 9 No. 3, pp. 312-326, available at: https://doi.org/10.1108/14601060610678176

van der Have, R.P. and Rubalcaba, L. (2016), "Social innovation research: an emerging area of innovation studies?”, Research Policy, Vol. 45 No. 9, pp. 1923-1935, available at: https://doi.org/ 10.1016/j.respol.2016.06.010

van Wijk, J., Zietsma, C., Dorado, S., de Bakker, F.G.A. and Martí, I. (2019), "Social innovation: integrating micro, meso, and macro level insights from institutional theory", Business and Society, Vol. 58 No. 5, pp. 887-918, available at: https://doi.org/10.1177/0007650318789104

Voorberg, W.H., Bekkers, V.J.J.M. and Tummers, L.G. (2015), “A systematic review of co-creation and co-production: embarking on the social innovation journey", Public Management Review, Vol. 17 No. 9, pp. 1333-1357, available at: https://doi.org/10.1080/14719037.2014.930505

Wagner, P. and Wilhelmer, D. (2017), "An integrated transformative process model for social innovation in cities", Procedia Eng., Urban Transitions Conference, Shanghai, September 2016 198, pp. 935-947, available at: https://doi.org/10.1016/j.proeng.2017.07.139

Ziegler, R. (2017), "Social innovation as a collaborative concept", Innovation: The European Journal of Social Science Research, Vol. 30 No. 4, pp. 388-405, available at: https://doi.org/10.1080/ 13511610.2017.1348935

Corresponding author

Laura Temmerman can be contacted at: laura.temmerman@vub.be

For instructions on how to order reprints of this article, please visit our website:

www.emeraldgrouppublishing.com/licensing/reprints.htm

Or contact us for further details: permissions@emeraldinsight.com 